\title{
Isolation of ethanol-induced genes in pancreatic $\beta$-cells by representational difference analysis (RDA)
}

\author{
Jun-Seop Shin ${ }^{1}$, Young-Sam Kwon ${ }^{2}$ \\ Jae-Jeong Lee ${ }^{1}$ and Chan-Wha Kim ${ }^{1,3}$ \\ ${ }^{1}$ Graduate School of Life Sciences and \\ Biotechnology \\ Korea University, Seoul 136-701, Korea \\ ${ }^{2}$ Department of Ophthalmology \\ Chung-Ang University \\ Seoul 140-757, Korea \\ ${ }^{3}$ Corresponding author: Tel, 82-2-3290-3439; \\ Fax, 82-2-3290-3957; E-mail, cwkim@korea.ac.kr \\ Accepted 16 December 2003
}

Abbreviations: DP, difference product; EtOH, ethanol; IAP, intracisternal A particle; IDH2, Isocitrate dehydrogenase 2; RDA, representational difference analysis; RPS3, ribosomal protein S3

\begin{abstract}
Recent epidemiological studies suggest that alcohol consumption is one of the risk factors leading to type 2 diabetes, but the direct effect of ethanol on $\beta$-cell gene expression is not known. Here, using cDNA RDA method, we isolated 43 ethanolinduced genes in pancreatic $\beta$-cells, and confirmed their differential expression by Northern blot or semi-quantitative RT-PCR. These genes were further categorized by the functional criteria based on the published data; Translation, Transcription, Metabolism, Signal transduction, Transport, Structure, Cytoskeleton, Regulation, or Putative/Unknown genes. The effects of each gene on $\beta$-cell function need to be further investigated, however, the present data strongly suggest that these genes might be related to the metabolic alterations caused by ethanol as indicated in earlier study. In particular, RPS3 gene expression was increased by ethanol, glucosamine, and cytokines, implying that ethanol might decrease the metabolic activity by oxidative stress in $\beta$-cells. Therefore, cloning of these genes in full-length and the detailed studies of each gene on $\beta$-cell functions might provide clues on the pathophysiology of type 2 diabetes caused by alcohol.
\end{abstract}

Keywords: differential expression; ethanol; pancreatic $\beta$-cell; RDA; type 2 diabetes

\section{Introduction}

Although various epidemiological studies suggest that alcohol intake is one of the risk factors leading to type 2 diabetes (Wei et al., 2000; Linda Kao et al., 2001), the effects of alcohol on insulin secretion and glucose tolerance are not fully understood. Previous reports have shown that ethanol exerts an inhibitory effect on glucose-stimulated insulin secretion in isolated rat islets (Patel and Singh, 1979) or in perfused rat pancreata (Tiengo et al., 1981), but these findings were quite contradictory to the similar studies on human (Metz et al., 1969; Friedenberg et al., 1971; Kuhl and Anderson, 1974): Ethanol augmented glucose-stimulated insulin secretion termed as 'ethanol priming effect' in the human (Metz et al., 1969). Recently, our results suggest that the ethanol priming effect on insulin secretion in pancreatic $\beta$-cells might be caused by overwork in order to compensate for the inhibited basal insulin secretion by ethanol (Shin et al., 2002).

As the pleiotropic effect of ethanol was mediated by the alterations in gene expression (Diamond and Gordon, 1997), a comprehensive and non-biased assessment of the effects of ethanol on gene expression should be considered. To this end, others have used a variety of methods to isolate the differentially expressed ethanol-responsive genes in cell culture (Miles et al., 1994; Rahman and Miles, 2001) and animal model systems (Tunici et al., 1999), including subtractive hybridization, DNA microarray, and differential display PCR (DD-PCR). Nevertheless, the direct effect of ethanol on the $\beta$-cell gene expression has not yet been reported. In the present study, therefore, we used the cDNA RDA method to clone ethanol-induced genes, and to seek for the causal relationship of these genes to ethanol-mediated metabolic alterations in pancreatic $\beta$-cells (HIT cells).

\section{Materials and Methods}

\section{Materials}

Oligonucleotides used in CDNA RDA were obtained from Gibco BRL (Grand Island, NY), and their sequences were as follows: R-Bgl-24 5'-AGCACTCT CCAGCCTCTCACCGCA-3', R-Bgl-12 5'-GATCTGCG GTGA-3'; J-Bgl-24 5'-ACCGA CGTCGACTATCCATG 
AACA-3', J-Bgl-12 5'-GATCTGTTCATG-3'; N-Bgl-24 5'AGGCAACTGTGCTATCCGAGGGAA-3', N-Bgl-12 5'-G ATCTTCCCTCG-3'.

Restriction and modifying enzymes were from Gibco BRL and New England Biolabs, Inc. (Beverly, $\mathrm{MA}$ ). Oligo (dT) spin column and plasmid miniprep kit were from Qiagen, Inc. (Valencia, CA). pGEM-T vector was purchased from Promega Corp. (Madison, WI).

\section{Measurement of ethanol}

One hundred $\mu$ of media following the addition of ethanol to the dish without or with cells were withdrawn at the indicated time points as shown in Figure 1 , and used to measure the ethanol concentrations. Ethanol concentrations were measured in duplicate samples with ethanol assay kit (Sigma Chemical Co. St. Louis, MO) according to the manufacturer's recommendations.

\section{General methods}

All common techniques and routine DNA manipulations, including transformation, plasmid preparation, gel electrophoresis were carried out according to the standard procedures (Sambrook et al., 1989). Restriction and modifying enzymes were used by manufacturer's instructions.

\section{cDNA RDA}

Total RNA was isolated from ethanol-treated and untreated cells, and further selected with oligo (dT) spin column for mRNA isolation. Double-stranded cDNA (2 $\mu \mathrm{g}$ ) was used in cDNA RDA process as described in (Hubank and Schatz, 1994) with minor modifications. Difference product 2 (DP2) with intact N-Bgl24 adapter was ligated with PGEM-T vector, and ligation mixture was used for transformation into competent E. coli XL-1 Blue cells. Double-stranded plasmid DNA was isolated, and sequence was determined by the dideoxy terminator cycle sequencing. Nucleotide sequences were compared to public databases by using BLAST service provided by National Center for Biotechnology Information (Bethesda, MD).

\section{Northern blot}

Total RNA $(20 \mu \mathrm{g})$ was fractionated on $1.2 \%$ agaroseformaldehyde gels and transferred overnight onto nylon membranes (Schleicher\& Schuell, Keene, NH) by capillary action, and baked at $120^{\circ} \mathrm{C}$ for $40 \mathrm{~min}$ before prehybridization. cDNA probes were made using dioxigenin (DIG)-High Prime DNA labeling kit (Roche Diagnostics Corp., Indianapolis, IN). The membranes were hybridized with dioxigenin-labeled probes overnight at $42^{\circ} \mathrm{C}$ in a solution containing $50 \%$ for- mamide, $5 \times$ SSC, $50 \mathrm{mM}$ sodium phosphate buffer $(\mathrm{pH} 7.0), 7 \%$ SDS, $0.1 \% \mathrm{~N}$-lauroylsarcosine, and $2 \%$ blocking reagent. All Northern blots were subjected to stringent washing conditions $(0.5 \times S S C, 0.1 \%$ SDS at $68^{\circ} \mathrm{C}$ ) before the immunological detection.

\section{Semi-quantitative RT-PCR}

Total RNA was extracted with Trizol reagent (Invitrogen), and the first strand CDNA was synthesized out of $2 \mu \mathrm{g}$ of the total RNA in $20 \mu \mathrm{l}$ reaction mixture, containing Superscript II RNase $\mathrm{H}^{-}$reverse transcriptase and oligo (dT) $)_{18}$ primer. Target regions were then amplified in a $20 \mu \mathrm{l}$ of volume for $25-28$ cycles using the following schedule: $1 \mathrm{~min}$ at $94^{\circ} \mathrm{C}$ followed by 30 cycles of $1 \mathrm{~min}$ at $94^{\circ} \mathrm{C}, 50 \mathrm{~s}$ at $57-59^{\circ} \mathrm{C}, 1 \mathrm{~min}$ at $72^{\circ} \mathrm{C}$, and a final extension step of $10 \mathrm{~min}$ at $72^{\circ} \mathrm{C}$. Primer sequences and detailed conditions for each gene are available upon the request. PCR products were run on a preparative 1.5 or $2 \%$ agarose gel, and the bands were photographed.

\section{Cellular stresses}

To measure the expression level of RPS3 gene under the cellular stresses, HIT cells were treated with 100 $\mathrm{mM}$ ethanol, $5 \mathrm{mM}$ glucosamine, and cytokine mixture $(400 \mathrm{U} / \mathrm{ml}$ TNF- $\alpha$ and $100 \mathrm{U} / \mathrm{ml} \mathrm{IFN}-\gamma)$ for $24 \mathrm{~h}$. Also, cells were treated with $1 \mathrm{mM} \mathrm{H}_{2} \mathrm{O}_{2}$ and $2.2 \mathrm{mM}$ streptozotocin (STZ) for $1 \mathrm{~h}$ and $30 \mathrm{~min}$, respectively. Following the treatment, total RNA was extracted, and Northern blot was performed as described above.

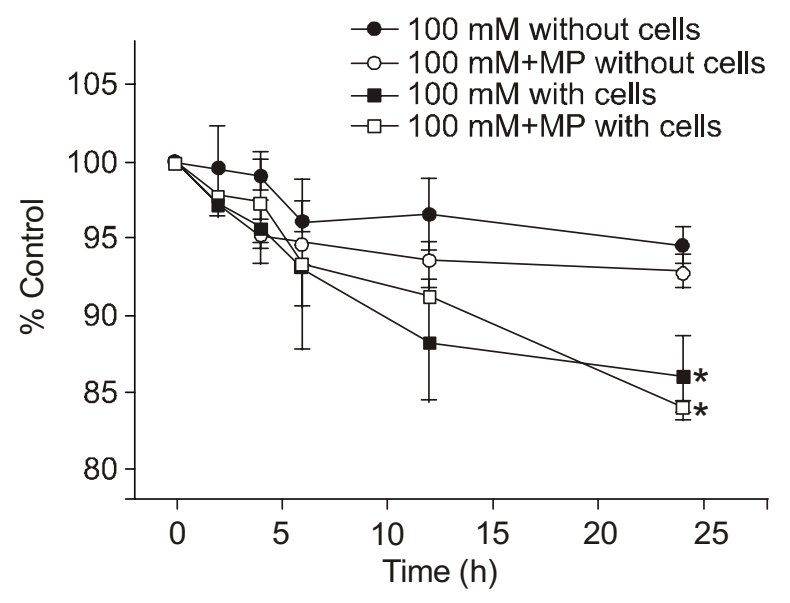

Figure 1. Ethanol concentrations over the culture period. HIT cells were treated with $100 \mathrm{mM}$ ethanol either in the absence or presence of $10 \mathrm{mM}$ 4-methyl pyrazole (MP). In control experiments, culture dish without cells was used. Values are mean \pm SEM of 4 independent experiments. ${ }^{*} P<0.001$ vs control dish without cells by Student's unpaired $t$ test. 


\section{Statistics}

Bands from Northern or RT-PCR were scanned with flat-bed scanner, and digitized using Scion image analysis software (Scion Corp., Frederick, MD, USA). Ethanol concentration is shown as means \pm standard error of the mean (SEM), and statistical significance was evaluated by unpaired Student's $t$ test.

\section{Results}

\section{Ethanol evaporation was negligible, and only minor fraction of ethanol was metabolized in HIT cells}

Ethanol is soluble in both water and lipid, and is readily distributed into the cytoplasmic and lipid membrane fractions of all cells (Diamond and Gordon, 1997). To determine the amount of ethanol evaporated from culture dish, and the amount directly exerted on the cells, ethanol concentration was measured during the incubation period. Ethanol concentration was $94.1 \pm$ $1.8 \%$ of the initial concentration after $24 \mathrm{~h}$ in the culture dish without cells, but the value was $85.0 \pm 2.2 \%$ in the presence of HIT cells. Also, ethanol concentration was not significantly different between methyl pyrazole (MP)-treated and untreated samples, despite the overall higher value was obtained MP-treated samples (Figure 1). Collectively, these results strongly suggest that only minor fraction of ethanol could be metabolized in HIT cells, and ethanol-metabolizing activity is not mediated by alcohol dehydrogenase.

\section{Ethanol-induced genes were isolated by cDNA RDA method}

We have previously shown that ethanol up to $100 \mathrm{mM}$ inhibited the activity of mitochondrial dehydrogenase in dose- and time-dependent manners (Shin et al.,

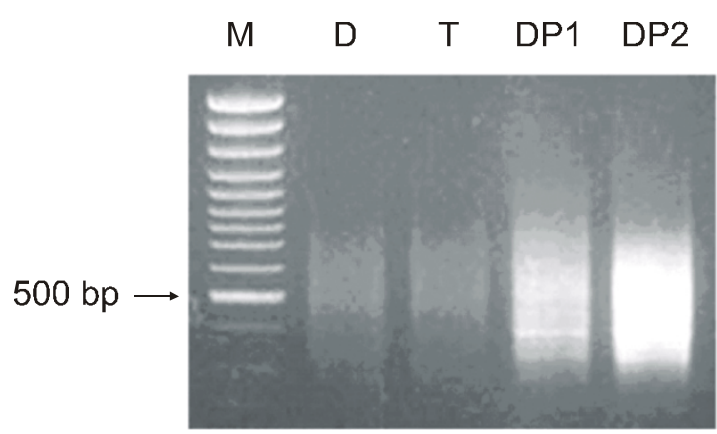

Figure 2. Ethidium bromide-stained agarose gel of driver (D), tester (T), difference products 1 (DP1), and difference products 2 (DP2) amplicons from cultured HIT cells. Driver and tester amplicons were generated from untreated control and ethanol-treated cells, respectively. Molecular size marker (M, 100 bp ladder) is shown in lane 1.
2002). Based on these results, HIT cells were treated with $100 \mathrm{mM}$ ethanol for $24 \mathrm{~h}$ prior to RNA isolation for cDNA RDA process. Two separate experiments were carried out to screen for genes that are induced by ethanol using untreated control CDNA as the driver, and one of these experiments is shown in Figure 2. Because double-stranded cDNA from untreated control and ethanol-treated cells were digested with 4-cutter enzyme Dpn II, driver and tester amplificons equally showed their size distribution ranging from $-100 \mathrm{bp}$ to $-700 \mathrm{bp}$ (lane 2 and 3 in Figure 2). When untreated control cDNA was used as driver for two rounds of denaturation, reannealing with tester cDNA from the ethanol-treated cells, and PCR amplification, the specific bands showing the enrichment of different products appeared on the gel [lane 4 (DP1) and 5 (DP2) in Figure 2]. To circumvent the technical difficulties in separating closely apposed bands, these DP2s were ligated with pGEM-T vector, and transformed into $E$. coli. Total 100 bacterial clones harboring recombinant plasmids were randomly selected, and plasmid DNA sequences were determined. Upon DNA homology search using BLAST program, total 43 independent genes were identified, and further categorized by the functional criteria based on the published data (Table 1). To confirm the differential expression,

\begin{tabular}{|c|c|c|}
\hline \multicolumn{2}{|c|}{$\mathrm{EtOH}$} & \\
\hline- & + & \\
\hline & 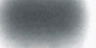 & Intracisternal A particle \\
\hline 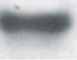 & 60 & Calmodulin 1 \\
\hline & sing & Ribosomal protein S3 \\
\hline & $=$ & Cytochrome P450 1A1 \\
\hline & 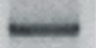 & Isocitrate dehydrogenase 2 \\
\hline & $=0$ & $26 \mathrm{~S}$ proteasome, subunit p112 \\
\hline & 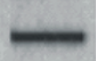 & Exportin \\
\hline & $=$ & Selective hybridizing clone \\
\hline & 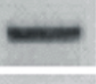 & $\begin{array}{l}\text { Eukaryotic translation initiation factor, } \\
\text { gamma } 1\end{array}$ \\
\hline & - & G protein pathway suppressor 1 \\
\hline
\end{tabular}

Figure 3. Differential expression of ethanol-induced genes in HIT cells. Total RNA was isolated from untreated and ethanol-treated cells, and their expression level was examined by Northern blot or semi-quantitative RT-PCR. Data was a representative of two independent experiments. 
Table 1. Ethanol-induced genes in HIT cells.

\begin{tabular}{|c|c|c|c|c|}
\hline Functional category and Name & Hmgy $(\%)^{a}$ & GenBank ID & $\mathrm{Fqy}^{\mathrm{b}}$ & $\begin{array}{l}\text { Induction } \\
\text { (-fold })\end{array}$ \\
\hline \multicolumn{5}{|l|}{ Translation } \\
\hline Ribosomal protein S3 (RPS3) & 91 & BC034149 & 5 & 1.5 \\
\hline Ribosomal protein L14 (RPL14) & 91 & NM_022949 & 5 & 1.3 \\
\hline Eukaryotic translation initiation factor 4 , gamma 1 (Eif4g1) & 90 & XM_359230 & 1 & 5.3 \\
\hline Similar to mitochondrial ribosomal protein $L 2$ & 90 & XM_217355 & 1 & 2.3 \\
\hline \multicolumn{5}{|l|}{ Transcription } \\
\hline Similar to bromodomain PHD finger transcription factor & 85 & XM_221050 & 1 & 45.3 \\
\hline C-terminal binding protein 2 (Ctbp2) & 93 & NM_053335 & 1 & 9.7 \\
\hline Transcription factor 12 & 80 & BC037097 & 1 & $N D^{d}$ \\
\hline \multicolumn{5}{|l|}{ Metabolism } \\
\hline Ubiquitin-like 1 (sentrin) activating enzyme E1B (Uble1b) & 90 & BC054768 & 2 & 5.7 \\
\hline Isocitrate dehydrogenase $2(N A D P+)$, mitochondrial (Idh2) & 89 & BC060030 & 1 & 6.0 \\
\hline Acetyl-CoA transporter (Acatn) & 89 & NM_022252 & 1 & 3.9 \\
\hline Phosphoglycerate mutase 1 & 97 & NM_023418 & 1 & ND \\
\hline Cytochrome P450 1A1 & 98 & D12977 & 1 & 5.3 \\
\hline \multicolumn{5}{|l|}{ UDP-N-acetyl-alpha-D-galactosamine:polypeptide } \\
\hline $\mathrm{N}$-acetylgalactosaminyltransferase 2 & 92 & BC059818 & 1 & 38.6 \\
\hline \multicolumn{5}{|l|}{ Signal transduction } \\
\hline Calmodulin 1 & 93 & BC054805 & 8 & 1.7 \\
\hline G protein pathway suppressor 1 (Gps1) & 94 & NM_145370 & 2 & 6.1 \\
\hline ADP-ribosylation-like 2 binding protein (Arl2bp) & 89 & BC024708 & 1 & ND \\
\hline Hsp70-interacting protein (St13) & 93 & NM_031122 & 1 & ND \\
\hline Nerve growth factor receptor (TNFRSF16) associated & & & & \\
\hline protein 1 (Ngfrap1) & 92 & BC058503 & 1 & 1.3 \\
\hline Neurotrophin receptor interacting factor 2 & 88 & AJ319726 & 1 & 7.0 \\
\hline \multicolumn{5}{|l|}{ Transport } \\
\hline Exportin (nuclear export receptor for tRNAs) & 88 & XM_125902 & 3 & 6.6 \\
\hline Secretory carrier membrane protein 5 (Scamp5) & 83 & NM_020270 & 1 & ND \\
\hline \multicolumn{5}{|l|}{ Structural genes } \\
\hline Structure specific recognition protein 1 & 93 & XM_342457 & 1 & 4.9 \\
\hline Heterogeneous nuclear ribonucleoprotein A2/B1 (Hnrpa2b1) & 93 & XM_342684 & 1 & 10.1 \\
\hline Signal recognition particle 9 (Srp9) & 85 & BC039648 & 1 & 3.2 \\
\hline Nucleosome assembly protein 1-like 1 (Nap1/1) & 93 & XM_346790 & 1 & 2.5 \\
\hline \multicolumn{5}{|l|}{ Cytoskeleton } \\
\hline Thymosin $\beta 4$ & 93 & BC018286 & 6 & 1.3 \\
\hline Dynein cytoplasmic light chain 1 & 96 & BC008106 & 2 & 2.6 \\
\hline \multicolumn{5}{|l|}{ Regulatory genes } \\
\hline Intracisternal A particle (IAP) & 97 & M10134 & 13 & 3.8 \\
\hline
\end{tabular}


Table 1. Continued.

\begin{tabular}{|c|c|c|c|c|}
\hline Functional category and Name & Hmgy $(\%)^{a}$ & GenBank ID & $\mathrm{Fqy}^{\mathrm{b}}$ & $\begin{array}{l}\text { Induction } \\
\text { (-fold) }\end{array}$ \\
\hline TBC1 domain family, member 8 & 88 & NM_018775 & 2 & 7.9 \\
\hline $26 S$ proteasome, subunit p112 & 97 & NM_031978 & 1 & 5.0 \\
\hline Islet amyloid polypeptide & 100 & $\mathrm{X} 56067$ & 1 & 1.4 \\
\hline \multicolumn{5}{|l|}{ 3-monooxgenase/tryptophan 5-monooxgenase activation } \\
\hline protein, gamma polypeptide & 90 & NM_018871 & 1 & 6.5 \\
\hline \multicolumn{5}{|l|}{ Putative or unknown } \\
\hline RIKEN cDNA 4930429H24 gene (4930429H24Rik) & 89 & XM_358791 & 2 & ND \\
\hline RIKEN cDNA 2410044K02 gene & 92 & BC019603 & 2 & ND \\
\hline RIKEN cDNA E130113K22 gene (E130113K22Rik) & 94 & NM_178718 & 1 & ND \\
\hline Selective hybridizing clone & 91 & BC054429 & 1 & 7.7 \\
\hline Pituitary tumor-transforming 1 (PTTG1) & 93 & NM_004219 & 1 & ND \\
\hline$R W 1$ protein & 83 & NM_018872 & 1 & ND \\
\hline Inhibitor of four 2 & 86 & AY245001 & 1 & ND \\
\hline Similar to KIAA1317 protein & 89 & XM_356997 & 1 & ND \\
\hline Hypothetical protein LOC217228 (LOC217228) & 96 & XM_126763 & 1 & ND \\
\hline Hypothetical TPR repeat containing protein & 88 & AK016428 & 1 & ND \\
\hline Hypothetical protein FLJ11280 & 90 & BC032321 & 1 & ND \\
\hline ERATO Doi 363, expressed, mRNA & 90 & BC029154 & 1 & ND \\
\hline RIKEN cDNA D030041l09 gene (D030041l09Rik) & 86 & NM_175460 & 1 & ND \\
\hline
\end{tabular}

${ }^{a} \mathrm{Hmgy}$ (homology), percent homology of the sequenced clone with the GenBank sequence listed; ${ }^{b} \mathrm{Fqy}$ (frequency), number of times the sequence was selected in the screening process; 'Induction, induction level of each gene analyzed in Northern blot or semi-quantitative RT-PCR; ${ }^{d}$ ND, differential expression of these clones is not tested because the retrieved sequences were not adequate to design the primer.

Northern blot or semi-quantitative RT-PCR was performed. Among those genes examined, the differential expressions of representative IAP, calmodulin-1, RPS3, CYP450 1A1, IDH2, 26S proteasome subunit p112, exportin, selective hybridizing clone, EIF4G 1, and GPS 1 were shown in Figure 3; Each gene was increased by 3.8-, 1.7-, 1.5-, 5.3-, 6.0-, 5.0-, 6.6-, 7.7-, $5.3-$, and 6.1 -fold in the ethanol-treated cells in comparison with those of untreated controls, respectively (Figure 3).

\section{RPS3 gene was increased by other cellular stresses}

Recently, RPS3 has been shown to function as a DNA repair enzyme, UV endonuclease III, which cleaves DNA damaged by UV. It also has an endonuclease activity on apurinic DNA (Jung et al., 2001). Since the $\beta$-cells are well known to have extremely low levels of anti-oxidative enzymes such as glutathione peroxidase, superoxide dismutase, and catalase (Lortz et al., 2000), we tested whether RPS3 gene increased its expression against the various

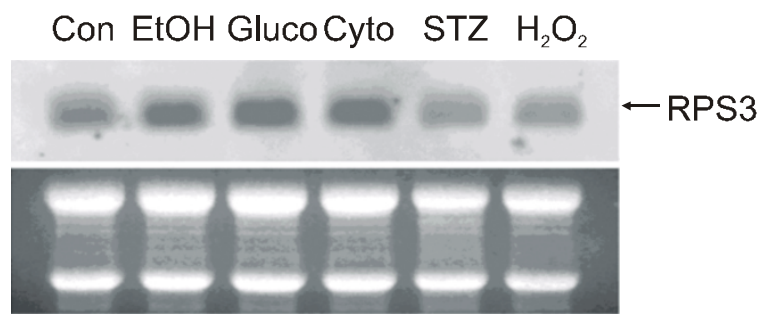

Figure 4. The effect of the cellular stresses on RPS3 gene expression. HIT cells were treated as described in Materials and Methods, and RPS3 was detected with digoxigenin-labeled cDNA probes. Low panel shows equal amount of RNA loading and intact RNA quality.

cellular stresses. As shown in Figure 4, RPS3 gene was increased by ethanol (1.5-fold), glucosamine (1.8fold), and cytokine mixture (1.6-fold) compared to those of untreated controls. However, STZ and $\mathrm{H}_{2} \mathrm{O}_{2}$ did not increase RPS3 expression, suggesting that their toxicity toward the $\beta$-cells might be different from that of ethanol, glucosamine, or cytokines. 


\section{Discussion}

The present study was undertaken to seek for genes responsible for ethanol-mediated metabolic alterations in pancreatic $\beta$-cells. Although ethanol concentration used in the study exceeds the physiological level, the data shown in Figure 1 clearly demonstrated that $\beta$ cells metabolize small amount of ethanol, and suggested that alternative pathway (s) of ethanol metabolism is present in $\beta$-cells other than alcohol dehydrogenase. In this regard, it is notable that although CYP450 2E1 responsible for microsomal oxidation of ethanol was not expressed in HIT cells (data not shown), CYP1A1 was identified as one of ethanolinduced genes (Table 1), and increased by 5.3 -fold in ethanol-treated cells compared to untreated control (Figure 3). It remains to be elucidated whether CYP450 1A1 could specifically oxidize ethanol in pancreatic $\beta$-cells.

Under exposure of HIT cells to $100 \mathrm{mM}$ ethanol for $24 \mathrm{~h}, 43$ independent ethanol-induced genes were isolated by cDNA RDA method, and further categorized by the functional criteria. Also, their differential expressions were confirmed by Northern blot or semiquantitative RT-PCR analyses, thus showing the effectiveness of RDA for cloning differentially expressed genes. Among the genes tested, our primary focus was to find the genes, of which expression might have protective roles against oxidative stresses in $\beta$ cells.

RPS3 is a multifunctional protein having DNA repair capabilities acing on apurinic/apyrimidinic (AP) sites in DNA and a combined N-glycosylase/AP lyase activity recognizing 8-oxo-G and formamidopyrimidine guanine (FapyGua) lesions in DNA (Kelley et al., 2000). In our study, RPS3 was increased by 1.5 -fold in ethanol-treated cells compared to untreated control, implying that ethanol might cause oxidative stress in the $\beta$-cells with a similar mechanism to that found in the ethanol-induced testicular toxicity (Oh et al., 2002). Compatible with this notion, RPS3 expression was increased by other oxidative stresses such as glucosamine (Kaneto et al., 2001) and cytokines (MandrupPoulsen et al., 1993). Also, another important gene in support of such idea is the $\mathrm{NADP}^{+}$-dependent mitochondrial isocitrate dehydrogenase 2 (IDH2) recently found to be important for maintaining balanced redox potential by providing NADPH needed for GSH production against cellular oxidative damage (Kim and Park, 2003). The $\beta$-cells were well known to have extremely low levels of anti-oxidative enzymes, and thus more susceptible than other cells to oxidative stress (Lortz et al., 2000). Such findings may have an important implication in defining a possible role of RPS3 or IDH2 as a protective agent in the $\beta$ cells against the oxidative stress. Further study will be required to address this important possibility.

\section{Acknowledgment}

The authors would like to thank Dr. Sangduk Kim for her helpful discussions and critical review of this manuscript. Jun-Seop Shin is a recipient of Brain Korea 21 postdoctoral fellowship of Graduate School of Life Sciences and Biotehcnology, Korea University.

\section{References}

Diamond I, Gordon AS. Cellular and molecular neuroscience of alcoholism. Physiol Rev 1997;77:1-20

Friedenberg R, Metz R, Mako M, Surmacznska B. Differential plasma insulin response to glucose and glucagons stimulation following ethanol priming. Diabetes 1971;20: 397-403

Hubank M, Schatz DG. Identifying differences in mRNA expression by representational difference analysis of cDNA. Nucleic acid Res 1994;22:5640-8

Jung SO, Lee JY, Kim J. Yeast ribosomal protein S3 has an endonuclease activity on AP DNA. Mol Cells 2001;12: 84-90

Kaneto H, Xu G, Song KH, Suzuma K, Bonner-Weir S, Sharma A, Weir GC. Activation of the hexosamine pathway leads to deterioration of pancreatic beta-cell function through the induction of oxidative stress. J Biol Chem 2001;276: 31099-104

Kelley MR, Tritt R, Xu Y, New S, Freie B, Clapp DW, Deutsch WA. The Drosophila S3 multifunctional DNA repair/ ribosomal protein protects Fanconi anemia cells against oxidative DNA damaging agents. Mutat Res 2001;485:107-19

Kim SY, Park JW. Cellular defense against singlet oxygeninduced oxidative damage by cytosolic $\mathrm{NADP}^{+}$-dependent isocitrate dehydrogenase. Free Rad Res 2003;37:309-16.

Kuhl C, Anderson O. Glucose- and tolbutamide-mediated insulin response after preinfusion with ethanol. Diabetes 1974; 23:821-6

Linda Kao WH, Puddey IB, Boland LL, Watson RL, Brancati $\mathrm{FL}$. Alcohol consumption and the risk of type 2 diabetes mellitus. Am J Epidemiol 2001;154:748-57

Lortz S, Tiedge M, Nachtwey T, Karlsen AE, Nerup J, Lenzen $S$. Protection of insulin-producing RINm5F cells against cytokine-mediated toxicity through overexpression of antioxidant enzymes. Diabetes 2000;49:1123-30

Mandrup-Poulsen T, Zumsteg U, Reimers J, Pociot F, Morch L, Helqvist S, Dinarello CA, Nerup J. Involvement of interleukin 1 and interleukin 1 antagonist in pancreatic beta-cell destruction in insulin-dependent diabetes mellitus. Cytokine 1993;5:185-91

Metz R, Berger S, Mako M. Potentiation of the plasma insulin response to glucose by prior administration of alcohol; An apparent islet-priming effect. Diabetes 1969;18:517-22

Miles MF, Wilke N, Elliot M, Tanner W, Shah S. Ethanol- 
responsive genes in neural cells include the molecular chaperones GRP78 and GRP94. Mol Pharmacol 1994;46:873-9

Oh SI, Lee MS, Kim Cl, Song KY, Park SC. Aspartate modulates the ethanol-induced oxidative stress and glutathione utilizing enzymes in rat testes. Exp Mol Med 2002;34:47-52

Patel DG, Singh SP. Effect of ethanol and its metabolites on glucose mediated insulin release from isolated islets of rats. Metabolism 1979;28:85-9

Rahman S, Meles MF. Identification of novel ethanol-sensitive genes by expression profiling. Pharmacol Ther 2001; 92:123-34

Sambrook J, Fritsch EF, Maniatis M. Molecular cloning, 2nd Ed., 1989. Cold Spring Harbor Laboratory Press, New York.
Shin JS, Lee JJ, Yang JW, Kim CW. Ethanol decreases basal insulin secretion from HIT-T15 cells. Life Sci 2002; 70:1989-97

Tiengo A, Valerio A, Molinari M, Meneghel A, Lapolla A. Effect of ethanol, acetaldehyde, and acetate on insulin and glucagon secretion in the perfused rat pancreas. Diabetes 1981;30:705-9

Tunici P, Schiaffonati L, Rabellotti E, Tiberio L, Perin A, Sessa A. In vivo modulation of $73 \mathrm{kDa}$ heat shock cognate and $78 \mathrm{kDa}$ glucose-regulating protein gene expression in rat liver and brain by ethanol. Alcohol Clin Exp Res 1999;23:1861-7

Wei M, Gibbons LW, Mitchell TL, Kampert JB. Alcohol intake and incidence of type 2 diabetes in men. Diabetes Care 2000;23:18-22 